\title{
Patient and family management of mucositis in children and adolescents with Acute Lymphoblastic Leukemia undergoing chemotherapy in Qatar: A narrative review
}

\author{
Reni Anil, Vahe Kehyayan, Jessie M. Johnson \\ University of Calgary in Qatar, Doha, Qatar
}

Received: February 4, 2018

Accepted: April 1, 2018

Online Published: April 10, 2018

DOI: $10.5430 /$ jnep.v8n8p114

URL: https://doi.org/10.5430/jnep.v8n8p114

\begin{abstract}
Objective: Currently oral mucositis in children and adolescents is a growing concern and requires emphasis on dental care, initial and ongoing assessment of the oral cavity, oral care, tooth brushing and oral rinses, as well as pain management. The purpose of this narrative review is to highlight the need and to outline the importance of assessment, treatment and care of children and adolescents while they go through chemotherapy treatments. It is during this treatment that oral mucositis is most prevalent due to the breakdown of rapidly dividing cells.

Methods: Narrative review.

Results: Providing planned mouth care education to patients and parents is useful in preventing and managing oral mucositis. Conclusions: Oral mucositis affects more than $75 \%$ of children and adolescents undergoing chemotherapy and places a significant burden on patients and caregivers. Severity of oral mucositis can range from mild, painless tissue changes to bleeding ulcerations that may prevent oral intake of nutrients and require narcotic analgesics to control associated pain. Oral mucositis also leads to an increased risk of infection and often delays further chemotherapy regimens. The peer reviewed literature supports structured patient and family education.
\end{abstract}

Key Words: Oral mucositis, Oral care, Cancer, Acute lymphocytic leukemia, Children, Adolescents

\section{INTRODUCTION}

Cancer is a major public health problem worldwide. ${ }^{[1]}$ Among children five to 14 years of age, cancer is emerging as the second leading cause of death in Asia, Central and South America, North America, and the Middle East. ${ }^{[2]}$ In this age group, leukemia, brain cancer, and lymphoma are the most prevalent. Experts recommend that cancers in children and adolescents should be treated in specialized cancer centers. ${ }^{[2]}$ These specialized cancer centers have specialized multidis- ciplinary teams comprising medicine and nursing who will be able to respond to the individual needs of these children and their families. Acute lymphoblastic leukemia (ALL) accounts for about $25 \%$ of all childhood malignancies. ${ }^{[3]} \mathrm{A}$ ten-year report (1998-2007) on the incidence of leukemia in nationals in the Gulf Cooperation Council (GCC) countries, including Bahrain, Kuwait, Oman, Qatar, Saudi Arabia, and United Arab Emirates indicates $33.4 \%$ in males and $32.5 \%$ in females among children aged above zero to 14 years old. ${ }^{[4]}$

*Correspondence: Vahe Kehyayan; Email: vkehyaya@ucalgary.ca; Address: University of Calgary in Qatar, Doha, Qatar. 
A retrospective cohort study based on the cancer registry of the National Center for Cancer Care and Research (NCCCR) in Qatar from 1991-2006 reported an incidence rate of 11.4\% in males and $12.9 \%$ in females for all cancers in 100,000 populations in this age group. ${ }^{[1]}$ The incidence rate of cancer in Qatar is estimated to be about 12 per 100,000 children with half of these cancers being leukemia or brain tumours. ${ }^{[1]}$ Thus the purpose of this paper is to highlight the need for the importance of assessment, treatment and care of children and adolescents while they go through chemotherapy treatments. This narrative review is built on a constructionist framework. According to Papert and Harel's study, ${ }^{[5]}$ a constructionist framework involves building and constructing knowledge as we acquire it through reading the literature, it is through this lens this narrative review was created.

\section{BACKGROUND}

Despite advances in the treatment of childhood cancers and improved survival rates, caring for children undergoing cancer treatment is difficult for many families as well as for clinicians. Children with cancer may experience physical symptoms and psychological distress from the disease itself as well as from the side effects of its treatment. They may experience pain from medical procedures and anxiety related to hospitalization. ${ }^{[2]}$ ALL is the most common childhood malignancy in children under the age of $15 .{ }^{[6]}$ It represents about $75 \%$ of all newly diagnosed leukemias and $30 \%$ of all pediatric cancers. ${ }^{[5]}$ Chemotherapy is the primary treatment favored in childhood cancers. ${ }^{[7]}$ Although treatment with cytotoxic chemotherapy is proven to be highly effective, it can cause localized to generalized erythema, lesions, hemorrhage, and ulcerations to the mucosal membrane of the mouth creating significant burden to patients and care givers. ${ }^{[6,7]}$ An estimated $80 \%$ of children and about $40 \%$ $60 \%$ of children and adolescents with leukemia undergoing chemotherapy will experience some degree of oral lesions during treatment. ${ }^{[6,8]}$ Cancer treatments also have an impact on children's "developing dentition and on orofacial growth". ${ }^{[6]}$ Other adverse consequences of antineoplastic treatment may be fungal infection of the mouth, oral discomfort and pain, poor nutrition, increased hospital stays, and increased cost of treatment. ${ }^{[9]}$

Oral mucositis (OM) is defined as the "change in mucosal membrane of oral cavity secondary to chemotherapy, radiation, and hematopoietic cell transplantation, whether alone or in combination, that causes serious and life threatening side effects in many patients" (p. 405). ${ }^{[10]}$ Oral mucositis can occur either as a direct effect of drugs on oral mucosa or due to its indirect effect resulting from bone marrow and myelo-suppression manifested as severe neutropenia during treatment. ${ }^{[11]}$ Inflammation and oral ulceration may develop within seven to 14 days following therapy. ${ }^{[11]}$ The incidence of OM differs according to the type of cancer and its treatments. The prevalence of OM is three times greater in pediatric populations than in adults due to rapid cell division in children. ${ }^{[12]}$ The frequency and severity of OM is also higher in children with hematological malignancies compared with children suffering from other malignancies. ${ }^{[12]}$ However, the incidence and prevalence of OM in children undergoing chemotherapy for ALL in Qatar is difficult to estimate since no research to date has been done in Qatar determining the side effects of cancer therapy. Oral mucositis is the most significant adverse consequence of cancer therapy reported by patients and caregivers. The development of OM can lead to drug dose reduction, treatment delays, septicemia, and up to $40 \%$ increase in mortality of patients in severe cases. ${ }^{[12,13]}$

A majority of cancer centers practice mouth care protocols to prevent and treat $\mathrm{OM}$, but they vary in terms of uniformity in their treatment approaches based on evidence-based clinical recommendations. ${ }^{[12,13]}$ Evidence also suggests that clinicians' knowledge of oral care is limited ${ }^{[13]}$ Hence, there exists a need to implement oral care regimens in consensus with oncology clinicians and dental departments in hospitals in order to improve oral care standards. ${ }^{[14]}$ A narrative review of the literature was conducted for this research. Literature on oral care in cancer patients with mucositis undergoing chemotherapy was reviewed through a constructionist lens. A constructionism framework was used in this narrative review. It is defined as ${ }^{[15]}$ "views learning as building knowledge structures in a context in which the learner is consciously engaged, and that concepts can be understood by constructing them" (p. 52100). ${ }^{[16]}$ In reviewing the literature through such a constructionist lens, the authors were able to examine the most commonly reported factors related to assessing and treating oral mucositis in children and adolescents with ALL receiving chemotherapy.

\section{ASSESSMENT OF ORAL CARE IN CHIL- DREN AND ADOLESCENTS}

Overall patients should undergo routine dental assessments during cancer treatments. Evidence-based guidelines recommend that dental assessment and treatments to be done at three points in time: at time of diagnosis and during and after treatments. ${ }^{[17]}$ The guidelines suggest that all new patients diagnosed with cancer should be notified in the pediatric dental units for dental assessments prior to commencing treatment. They also suggest the availability of a pediatric dental unit liaising with cancer treatment centers or the provision of clear communication between cancer centers and the patient's dental practitioner. Further, they recommend 
follow up dental assessments every three to four months during their cancer treatment by the dental care provider. Dental care and follow-ups should be done throughout the patients' growth and development for proper dental and orofacial management. ${ }^{[17]}$ Identifying and treating oral problems before commencing treatment, and having an oral care plan in place during the cancer trajectory, along with routine dental follow ups thereafter, can prevent oral complications of cancer and its treatments.

\subsection{Tooth brushing}

Intensive oral hygiene care is effective in reducing the severity of and discomfort associated with OM by preventing oral complications and promoting good oral health. ${ }^{[11]} \mathrm{Pa}-$ tients and their parents should receive verbal and written instructions in oral hygiene prior to the initiation of cancer treatment. ${ }^{[17]}$ Oral hygiene care is a low cost intervention often under-utilized for the prevention of OM. ${ }^{[18]}$ However, evidence suggests that clinicians' knowledge of oral care is limited. ${ }^{[14]}$ Variability in baseline oral care practices must be acknowledged by clinicians and addressed with patients and families before a patient begins chemotherapy. Children and adolescents should be educated and encouraged to maintain good oral hygiene which include tooth brushing and use of mouthwash. ${ }^{[13]}$

Tooth brushing eliminates bacterial dental plaque and debris that contribute to local infection and development of OM in immunocompromised patients. ${ }^{[18]}$ Therefore, clinicians should encourage their patients to brush their teeth twice daily for at least two minutes using a soft nylon tooth brush. ${ }^{[14]}$ The tooth brush should be changed every two to three months and/or after a neutropenic episode. It should also be air-dried between uses. ${ }^{[14]}$ If the child has a sore mouth, they should be instructed to use a soft tooth brush with a small head. Brushing should be continued regardless of the patient's white blood cells and platelet counts. If platelet counts are between 20,000 and $50,000 / \mathrm{mm}^{3}$, patients should be instructed to use extra soft bristle toothbrushes. On the other hand, if the platelet count is $<20,000 / \mathrm{mm}^{3}$, patients should use a sponge toothette or a moist gauze. ${ }^{[14]}$ When patients have painful oral lesions, instead of tooth brushing the patient's teeth and gums should be wiped with sponges moistened in water, sodium bicarbonate, or chlorhexidine solutions. To reduce the possibility of bleeding following brushing teeth, gentle massage of the gums is advised. ${ }^{[18]}$ Children under the age of six years should perform brushing under the supervision of parents or caregivers. Therefore, parents or caregivers should be instructed on how to brush their child's teeth. They should also be given instructions on how to clean the mouth with moistened oral sponges. ${ }^{[18]}$
A small pea-sized mint-free fluoridated children's toothpaste of 400 ppm can be used for children from 18 months to six years. An adult standard mint-free fluoride toothpaste of $1,000 \mathrm{ppm}$ can be used for children over six years of age. No tooth paste is recommended for children less than 18 months of age and their mouth should be sponged using warm water. ${ }^{[14]}$ In addition, to keep the oral tissues clean, patients should rinse their mouths with cold water as often as possible; such action may decrease the risk of opportunistic infections. ${ }^{[18]}$

\subsection{Mouth wash}

Although Benzydamine and Chlorhexidine rinses have beneficial effects on oral mucositis in children, there is no evidence to support the effectiveness of one over the other, nor other rinses resulting in superior outcomes. ${ }^{[19]}$ Therefore, clinical decisions should consider the patient's unique mouth condition and preference. ${ }^{[19]}$ Rinsing the mouth twice daily with $10 \mathrm{ml}$ of prescribed mouthwash for 30 seconds after tooth brushing is effective in preventing infections. ${ }^{[14]}$ Infants and children who are unable to rinse their oral cavity should be cleaned by their caregivers using probes soaked in the recommended mouthwash to swab the mouth. ${ }^{[14]}$ Following episodes of emesis, the mouth should be rinsed with water or any bland solution to prevent gastric acids from decalcifying teeth enamel and irritating soft oral tissues. ${ }^{[5]}$ It can be concluded that mouthwashes may play an important part in reducing oral mucosal damage during chemotherapy, possibly through plaque control and reduction of oral microflora.

\subsection{Management of pain}

The most major side effect associated with OM is painful oral lesions. ${ }^{[20]}$ Pain from mucositis may decrease patient's ability to perform adequate oral care that may further increase ulceration and infection and can cause malnutrition and poor quality of life. ${ }^{[21]}$ Treatment of painful OM should begin promptly in an escalating stepwise pattern until the pain becomes tolerable. ${ }^{[19]}$ The fundamental level strategy of pain management of OM includes basic oral hygiene, oral care rinses, and trauma prevention. ${ }^{[19]}$ Persistent or increased OM pain should include adding topical anesthetics to the basic level oral care. If topical agents are non-effective, systemic analgesics should be considered in controlling pain related to OM. ${ }^{[19]}$ Patients should be give pain medication on a timecontingent basis and not as pain-contingent basis for better pain tolerance. ${ }^{[22]}$ Adding successive steps such as patient controlled analgesia and strong narcotic analgesics should be considered in order to maintain a steady state of analgesia. ${ }^{[22]}$ Prophylactic treatment of constipation must be considered if patients are prescribed opioids for pain management and 
the effectiveness of treatment should be frequently assessed by clinicians. ${ }^{[19]}$ The evidence from several studies support the use of low-energy level laser therapy in reducing pain related to OM significantly. ${ }^{[20,22-24]}$ Effective pain management would require ongoing assessment of the severity and nature of the pain, and where necessary, considerations of alternative therapeutic interventions.

\subsection{Mouth care education}

Mouth care education can is effective in reducing the severity of symptoms in OM. ${ }^{[11,25]}$ The Multinational Association of Supportive Care in Cancer (MASCC)/International Society for Oral Oncology (ISOO) "clinical practice guidelines for the management of mucositis secondary to cancer therapy" recommend mouth care protocols and patient education as effective modalities. ${ }^{[22]}$ They also recognize that monitoring the patient's mouth for symptoms of OM, providing mouth care, evaluating pain related using valid measurement scales, reinforcing mouth care education, and demonstrating mouth care using written and visual materials are the essential components of OM management. The clinicians should observe the normal brushing techniques of patients and explain to them the best way of brushing their teeth using a model tooth. Clinicians should explain to the children that they should place their toothbrush at an angle of 45 degrees at the meeting point of the tooth and gums. They should then sweep their toothbrush towards the chewing surface in order to clean the dental plaque on the buccal, lingual, and occlusal surfaces. According to the American Academy of Pediatric Dentistry, this technique will mechanically remove plaque and debris from their oral cavity and ensures oral hygiene. In a study by Yavuz and Yilmaz (2015) investigating the impact of mouth care education on the degree of OM in children, the researchers reported that $93.75 \%$ of the children were not performing mouth care regularly because they did not believe that practicing mouth care was a useful intervention in preventing OM. ${ }^{[26]}$ However, all study participants began performing mouth care following the education program. The results of the study showed a statistically significant difference between the degree of OM before and after the mouth care education $(p<.05)$.

\subsection{Grading of mucositis}

In clinical management settings, it is important to assure that oral assessments are conducted by clinicians in a uniform manner. ${ }^{[19]}$ Patients and families should also be trained to recognize the signs and symptoms of developing OM, thus enhancing appropriate and timely care. The WHO Oral Toxicity Scale is the most commonly used tool to assess OM in the published literatures. ${ }^{[27-29]}$ The revised version of this assessment tool ensures accurate monitoring and contains both objective and subjective elements. ${ }^{[30]}$ The clinical presentation of soreness +/- erythema with no ulceration is rated as Grade 1. Patients with erythema and ulcers with but able to swallow solid foods are rated as Grade 2. Those with ulcers, extensive erythema, and are unable to swallow solid foods are rated as Grade 3. Patients who are unable to take fluids and solids orally to the extent of receiving adequate nourishment are rated as Grade 4. ${ }^{[30]}$ Therefore, all treatment strategies aimed at improving mouth care are based on the accurate assessment of the patient's oral cavity.

\section{Conclusion}

Oral mucositis affects more than $75 \%$ of children and adolescents undergoing chemotherapy and represents a significant burden to them and their caregivers. Severity of OM can range from mild and painless tissue changes to bleeding ulcerations that may prevent the oral intake of food and require narcotic analgesics to control associated pain. Oral mucositis also leads to an increased risk of infection and often delays further chemotherapy regimens. Parents of children and adolescents are concerned about the impact of cancer and cancer treatments on their children and families. It is of utmost importance that each child and adolescent who has ALL and hence suffer from the side effects of chemotherapy such as mucositis be assessed and treated to avoid delays in cancer treatment. It is of equal importance that parents take an active role in the oral treatment of these patients as well.

\section{CONFLiCTS OF INTEREST Disclosure}

The authors declare that there is no conflict of interest.

\section{REFERENCES}

[1] Bener A, Ayub H, Kakil R, et al. Patterns of cancer incidence among the population of Qatar: A worldwide comparative study. Asian Pacific Journal of Cancer Prevention. 2008; 9(1): 19-24.

[2] American Cancer Society. Global Cancer Facts and Figures. (3rd ed.). 2015. Available from: http://www.cancer.org/acs/gro ups/content/@research/documents/document/acspc-044

Published by Sciedu Press 738.pdf

[3] Al-Mulla N, Chandra P, Khattab M, et al. Childhood acute lymphoblastic leukemia in the middle east and neighboring countries: A prospective multi-institutional international collaborative study (CALLME1) by the middle east childhood cancer alliance (MECCA). Pediatric Blood \& Cancer. 2014; 61(8): 1403-1410. PMid:24648275 https ://doi.org/10.1002/pbc. 25031 
[4] Cancer Incidence Report. Ten year cancer incidence among nationals of the GCC states 1998-2007. 2011. Available from: http://www.moh.gov.bh/pdf/publications/GCC $\% 20$ Cancer\%20Incidence\%202011.pdf

[5] Papert S, Harel I. Situating constructionism. In S. Papert \& I. Harel, Constructionism, (ch. 2). New York: Ablex Publishing Corporation; 1991.

[6] Valéra M, Noirrit-Esclassan E, Pasquet M, et al. Oral complications and dental care in children with acute lymphoblastic leukaemia. Journal of Oral Pathology \& Medicine. 2015; 44(7): 483-489. PMid:25243950 https://doi.org/10.1111/jop.12266

[7] Miller MM, Donald DV, Hagemann TM. Prevention and treatment of oral mucositis in children with cancer. The Journal of Pediatric Pharmacology and Therapeutics: JPPT: The Official Journal of PPAG. 2012; 17(4): 340-350. PMid:23413048 https://doi.org/10.5 863/1551-6776-17.4.340

[8] Nashwan AJ. Use of chlorhexidine mouthwash in children receiving chemotherapy: A review of literature. Journal of Pediatric Oncology Nursing: Official Journal of the Association of Pediatric Oncology Nurses. 2011; 28(5): 295-299. PMid:21821553 https://doi.org/10.1177/1043454211408103

[9] de OL, de OL, Alves CMC, et al. Chemotherapy-induced oral complications in leukemic patients. International Journal of Pediatric Otorhinolaryngology. 2007; 71(11): 1681-1685. PMid:17850887 https://doi.org/10.1016/j.ijporl.2007.07.006

[10] Clarkson JE, Worthington HV, Furness S, et al. Interventions for treating oral mucositis for patients with cancer receiving treatment. The Cochrane Library. 2010.

[11] Yarbro CH, Wujcik D, Gobel BH. Cancer symptom management. Jones \& Bartlett Learning. 2013.

[12] Chen C, Wang R, Cheng S, et al. Assessment of chemotherapyinduced oral complications in children with cancer. Journal of Pediatric Oncology Nursing: Official Journal of the Association of Pediatric Oncology Nurses. 2004; 21(1): 33-39. PMid:15058405 https://doi.org/10.1177/1043454203259947

[13] Allen G, Logan R, Gue S. Oral manifestations of cancer treatment in children: A review of the literature. Clinical Journal of Oncology Nursing. 2010; 14(4): 481-490.

[14] Farrington M, Cullen L, Dawson C. Evidence-based oral care for oral mucositis. ORL-Head and Neck Nursing: Official Journal of the Society of Otorhinolaryngology and Head-Neck Nurses. 2013; 31(3): 6-15.

[15] Qutob AF, Gue S, Revesz T, et al. Prevention of oral mucositis in children receiving cancer therapy: A systematic review and evidence-based analysis. Oral Oncology. 2013; 49(2): 102-107. PMid:22959949 https ://doi.org/10.1016/j.oraloncology .2012.08.008

[16] Carragher R, Johnson J, Harder M. Factors influencing bystander CPR: A narrative review. International Journal of Current Research. 2017; 9(6): 52100-52103.

[17] Glenny AM, Gibson F, Auld E, et al. The development of evidencebased guidelines on mouth care for children, teenagers and young adults treated for cancer. European Journal of Cancer. 2010; 46(8): 1399-1412. PMid:20227272 https://doi.org/10.1016/j.ej ca. 2010.01 .023

[18] Mathur VP, Dhillon JK, Kalra G. Oral health in children with leukemia. Indian Journal of Palliative Care. 2012; 18(1): 12-18.
PMid:22837605 https ://doi.org/10.4103/0973-1075.9734 3

[19] Bensinger W, Schubert M, Ang KK, et al. NCCN Task Force Report. prevention and management of mucositis in cancer care. Journal of the National comprehensive Cancer Network: JNCCN. 2008; 6 : S1-21.

[20] Amadori F, Bardellini E, Conti G, et al. Low-level laser therapy for treatment of chemotherapy-induced oral mucositis in childhood: A randomized double-blind controlled study. Lasers in Medical Science. 2016; 31(6): 1231-1236. PMid:27272517 https://doi.org/10.1 007/s10103-016-1975-y

[21] Cauwels RGEC, Martens LC. Low level laser therapy in oral mucositis: A pilot study. European Archives of Paediatric Dentistry: Official Journal of the European Academy of Paediatric Dentistry. 2011; 12(2): 118-123. https://doi.org/10.1007/BF03262791

[22] Lalla RV, Bowen J, Barasch A, et al. MASCC/ISOO clinical practice guidelines for the management of mucositis secondary to cancer therapy. Cancer. 2014; 120(10): 1453-1461. PMid:24615748 https://doi.org/10.1002/cncr. 28592

[23] Chermetz M, Gobbo M, Ronfani L, et al. Class IV laser therapy as treatment for chemotherapy-induced oral mucositis in oncohaematological paediatric patients: A prospective study. International Journal of Paediatric Dentistry. 2014; 24(6): 441-449. PMid:24372909 https : //doi.org/10.1111/ipd. 12090

[24] Oberoi S, Zamperlini-Netto G, Beyene J, et al. Effect of prophylactic low level laser therapy on oral mucositis: A systematic review and meta-analysis. Plos One. 2014; 9(9): e107418-e107418.

[25] Cheng KK, Chang AM, Yuen MP. Prevention of oral mucositis in paediatric patients treated with chemotherapy: A randomised crossover trial comparing two protocols of oral care. European Journal of Cancer. 2004; 40(8): 1208-1216. PMid:15110885 https : //doi.org/10.1016/j.ejca.2003.10.023

[26] Yavuz B, Bal Yilmaz H. Investigation of the effects of planned mouth care education on the degree of oral mucositis in pediatric oncology patients. Journal of Pediatric Oncology Nursing. 2015; 32(1): 47-56. PMid:25416516 https ://doi .org/10.1177/10434542145540 11

[27] Hodgson BD, Margolis DM, Salzman DE, et al. Amelioration of oral mucositis pain by NASA near-infrared light-emitting diodes in bone marrow transplant patients. Supportive Care in Cancer. 2012; 20(7): 1405-1415. PMid:21725826 https ://doi .org/10.1007/ s00520-011-1223-8

[28] Legert KG, Remberger M, Ringdén O, et al. Reduced intensity conditioning and oral care measures prevent oral mucositis and reduces days of hospitalization in allogeneic stem cell transplantation recipients. Supportive Care in Cancer. 2014; 22(8): 2133-2140. PMid:24647488 https ://doi.org/10.1007/s00520-014-219 $0-7$

[29] Leppla L, Geest S, Fierz K, et al. An oral care self-management support protocol (OrCaSS) to reduce oral mucositis in hospitalized patients with acute myeloid leukemia and allogeneic hematopoietic stem cell transplantation: A randomized controlled pilot study. Supportive Care in Cancer. 2016; 24(2): 773-782. PMid:26190359 https : //doi.org/10.1007/s00520-015-2843-1

[30] United Kingdom Oral Mucositis in Cancer Group. Guidelines. Mouth care guidance and support in cancer and palliative care. 2015. Available from: http://www.ukomic.co.uk/pdf/UK_OM_Guide lines_v3.pdf 